\section{'One woman is enough...'}

\author{
Few women reach \\ the uppermost rungs \\ of Japan's scientific \\ hierarchy. But some \\ are now starting to \\ challenge the system \\ and attitudes that \\ frustrate their career \\ progress, as David \\ Cyranoski discovered.
}

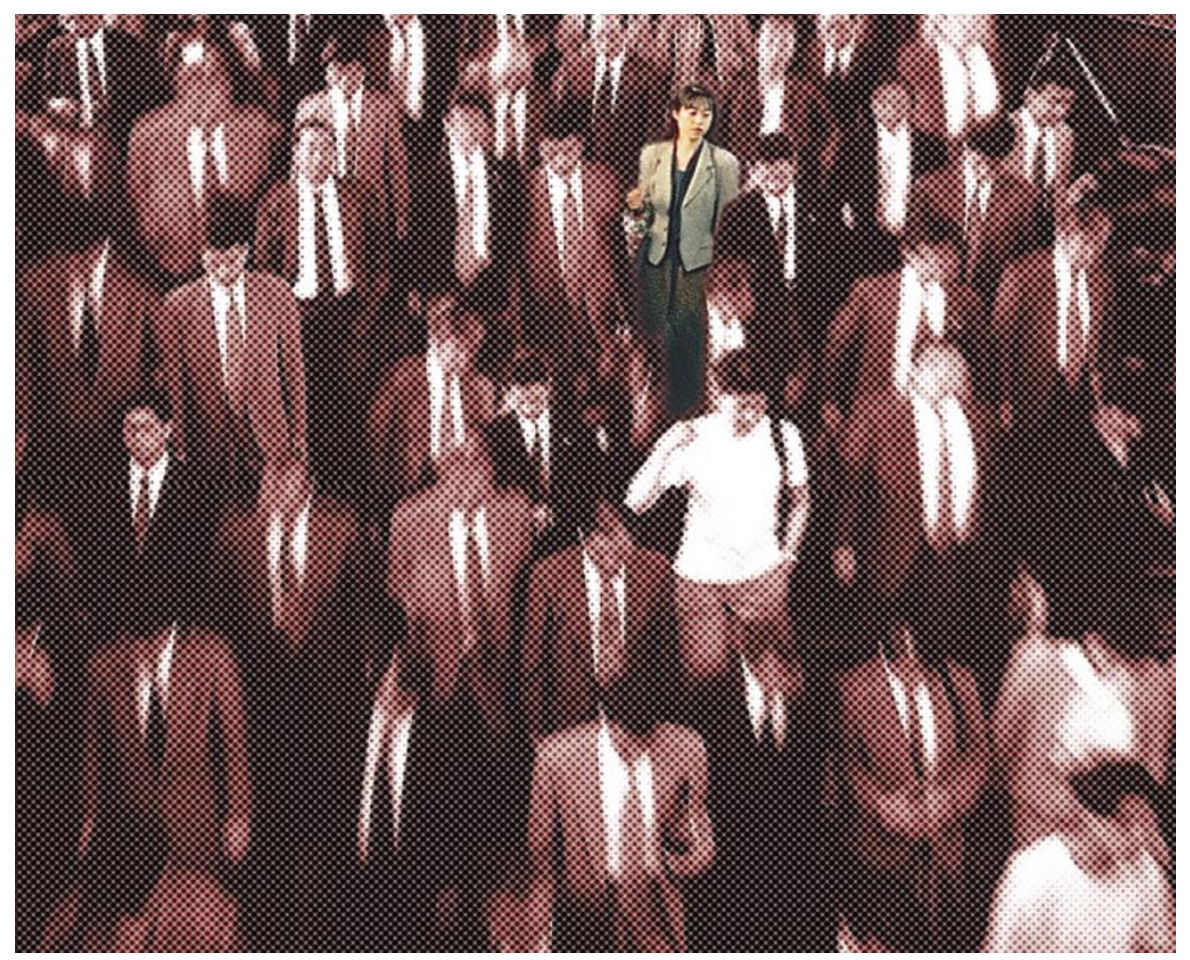

women among their research staff, have a better record than government labs $(8.4 \%)$ and industry (5.1\%). But even here they are overwhelmingly concentrated in the most junior positions. They may account for up to half of graduate students, postdocs and technicians, but a woman full professor is a rare

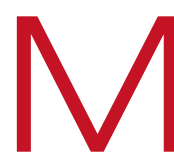

any Japanese men feel more comfortable without women as colleagues.

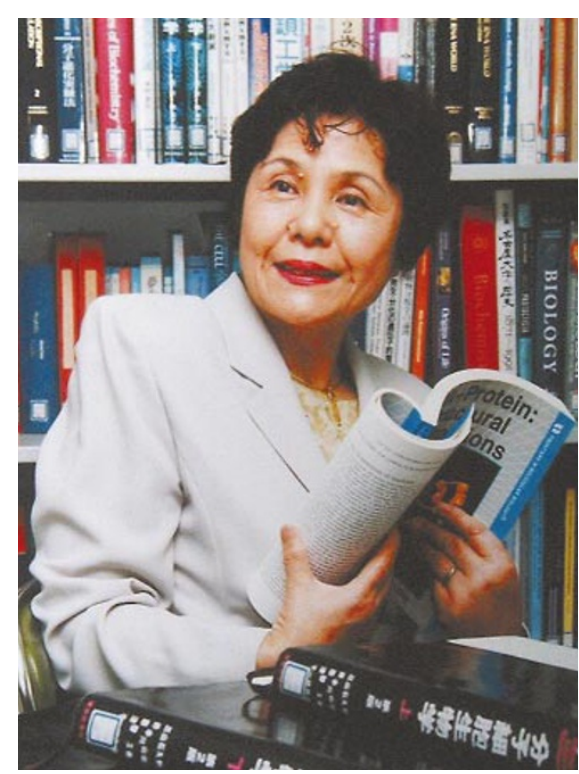

Mitiko Go has seen sex discrimination in action.

$\approx$ ๑ 2001 Macmillan Magazines Ltd thing indeed (see charts, overleaf).

Although the outlook remains bleak, some women scientists such as Go and Kato are now speaking out against these iniquities. And others are battling the odds and taking their cases to court. Last year, in a landmark decision, toxicologist Kumiko Ogoshi won a lawsuit against Nara Medical University for the harassment she faced after she set up an association of research associates - the lowest rung on the ladder of permanent academic positions - to examine the academic research system (see Nature 407, 935; 2000). Although Ogoshi was awarded only US $\$ 5,000$, the recognition in a court of law that harassment occurs in academia set an important precedent.

Another pending case is highlighting the plight of women scientists in temporary research posts, who often lack the security of a written contract. In 1997, a woman researcher on a three-year appointment at the National Institute for Longevity Sciences in Aichi, failed to receive a lucrative research grant that she believed she had been promised on taking the job. The grant was eventually distributed to another - male - researcher at the same institute. The plaintiff is now suing the government and her former boss for breach of promise and for harassment.

At the heart of the culture of discrimination, according to many women scientists, lies the ' $k o z a$ ' system, which places huge power in the hands of full professors. At Japanese universities, professors have almost complete control over funding and hiring decisions under their chair. Many of them are men with traditionalist attitudes which means that women face entrenched, but largely hidden barriers to advancement. 
"The restraints can't be seen, but when women go to the United States, they go away, and so the women stay there," says one researcher at RIKEN, the Institute of Physical and Chemical Research in Wako, who has seen many of her friends move abroad.

\section{Double standards}

In Japan, career advancement is usually the result of being called from above, rather than exerting pressure from below. Koza professors are supposed to look after the future of their students, but there are widespread complaints that the level of assistance and patronage provided is radically different for men and women. One indignant woman neuroscientist relates the story of a male colleague whose research suffered during a bout of depression. His mentor rescued his career by arranging a permanent position in the lab of a personal friend. "This just would not happen with a woman," says the researcher.

Professors like hiring women postdocs, says Go, who has heard colleagues express such opinions as: "They are good hard workers, and I don't have to worry about their future." And given a recent expansion in the number of postdoctoral posts, many more women are finding themselves stuck at the bottom of the career ladder, unable to get permanent positions. Indeed, while men advance up the academic ladder, women can be told that "your husband has a good position anyway", or "you will probably be getting married soon".

If jobs were advertised openly, the situation might not be so bad. But often they are not; and even if jobs are advertised, says Sonoko Habu, a professor of immunology at Tokai University School of Medicine, "they are often decided before that". Habu recalls being actively discouraged from applying for research associate positions by colleagues of her koza professor - they argued that men needed the jobs to support their families. Successful candidates, says Habu, usually owe their appointments to "personal relations - who your university classmates were or who your drinking buddies are". Japan's

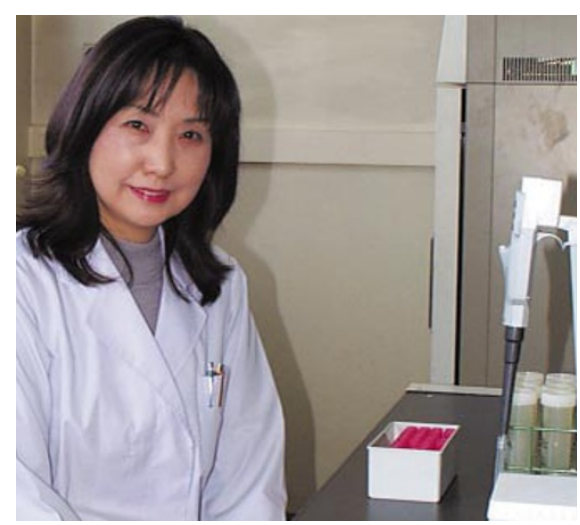

Beating the system: toxicologist Kumiko Ogoshi successfully sued her university for harassment.

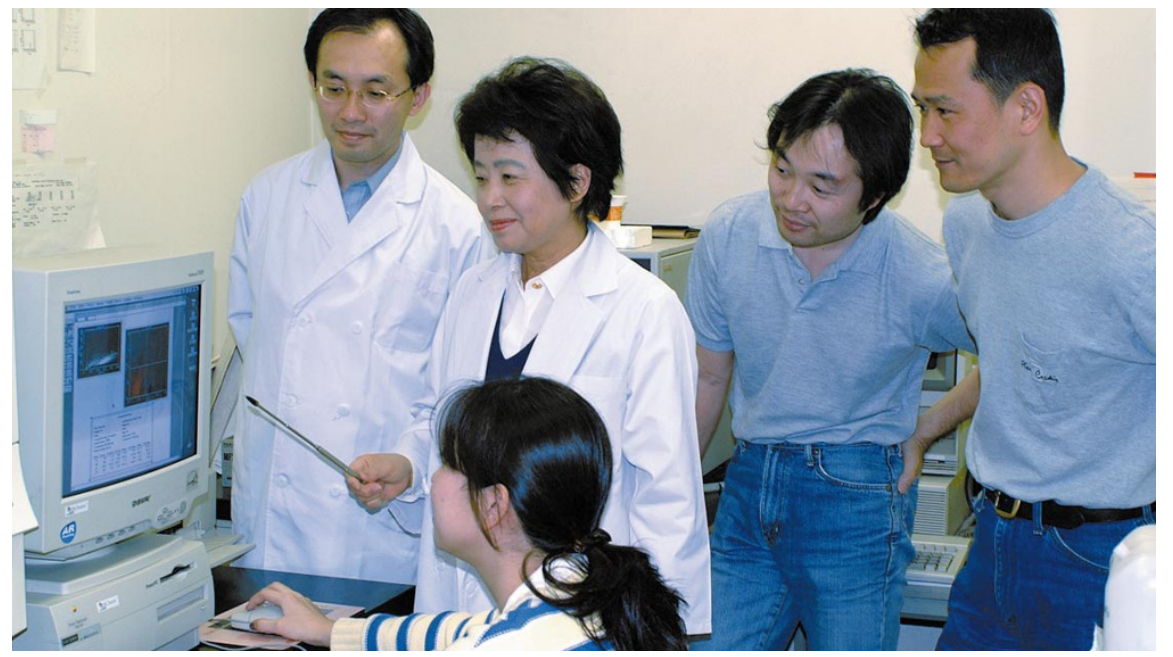

It's not what you know: Sonoko Habu (standing centre) feels personal relations influence promotions.

culture of after-work social drinking is almost exclusively male, so women are left out in the cold.

There is also the problem of credit on scientific papers. Women are less likely to be named as first author on a paper for which they contributed the bulk of the work, says Go. If they are, those evaluating the publications during hiring or grant decisions will often assume that the woman did not do the work but was given first authorship out of kindness by the lab head. Go was blessed with an understanding mentor and a field - theoretical and biophysical analysis of protein structures - that allowed her to do most of her work alone. So she was able to publish papers under her sole authorship. "Then there is no question," says Go.

The scientific career structure in Japan also makes few concessions to women who need to juggle the demands of career and family. "Anything that goes wrong at work is seen as an indication of too much commitment to one's family," says Noriko Mochizuki-Oda, a neuroscientist currently conducting research with short-term funding from industry at the Osaka Bioscience Institute. "You lose confidence."

Women who take a few years out to start a family run up against a system in which careers are expected to be established by one's early thirties. "But that is the most difficult age for women to focus on their research," says Mochizuki-Oda. What is more, many grants are only awarded to researchers in their mid-thirties or younger. "In Japan there is still the idea of lifetime employment and seniority-based promotion all starting when you are 30," says Junko Nakanishi, a full professor in environmental risk management at Yokohama National University.

Mothers also lose out from Japan's prevailing attitudes which judge hours worked as a measure of one's worth. "Assuming the results are about the same, research by a man who stays until midnight will be more highly praised than that by a woman who returns home in the early evening," says Yoichi Oda, Mochizuki-Oda's husband, himself a neuroscientist at Osaka University.

\section{What's in a name?}

Women fear that even getting married with its attendant stereotype of 'housewife' - can place them at a disadvantage. And regulations from the Ministry of Education, Culture, Sports, Science and Technology exacerbate the situation. Grants-in-aid for scientific research, the greatest source of funding for academic research in Japan, will not be given to married women who try to use their maiden name. As careers often depend on name recognition, many women resent what they see as coercion to abandon their 'professional' names. Go, Kato and others have repeatedly demanded that the ministry change its policy - and according to a ministry official, the restriction will be lifted before the next round of applications this autumn.

Officialdom is slowly realizing that reforms are needed. The Science Council of Japan, which advises the Cabinet on science and technology, last July announced that it would raise its female membership to $10 \%$ by 2010 . Soon afterwards, five more women

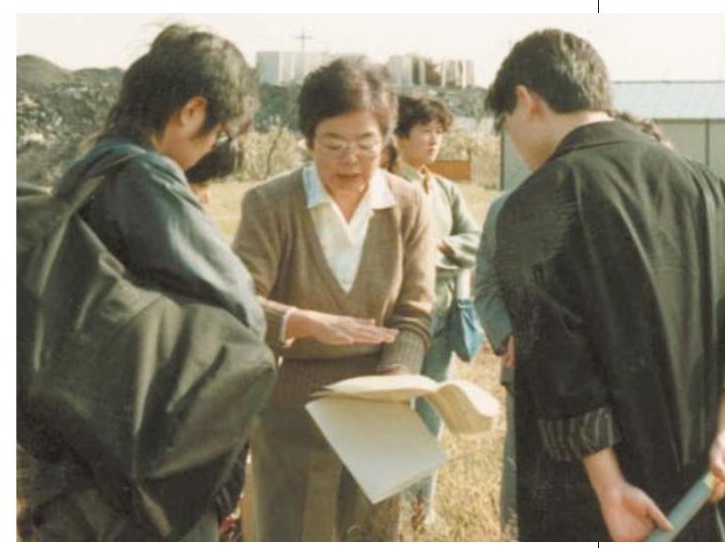

Junko Nakanishi is one of the few women to head a government-funded research centre. 


\section{news feature}

members were appointed, bringing the total to seven out of 210 . Government committees have been given a target to raise the proportion of women among their members to $30 \%$ by 2005. And the Japan Association of National Universities has set itself a 20\% target for permanent research positions by 2010. Currently, the figure stands at 7\%.

But these targets are not binding, and many women scientists doubt that they will be met. When the reorganized National Institute of Advanced Industrial Science and Technology (AIST) sought directors for its 45 new centres and institutes earlier this year, officials had in mind a $30 \%$ target. But only one female director - Nakanishi, who will head the Research Center for Chemical Risk Management in Tsukuba — was appointed. "We just could not find the qualified people," says a female AIST official. RIKEN similarly includes just one woman among its 56 chief scientists.

\section{Pressure point}

Given the slow progress, women scientists say that the pressure being exerted by prominent scientists such as Go and Kato, and by those women who are prepared to take their grievances to court, is extremely important.

The next focus of attention is likely to be on the pending action against the Aichi longevity institute. In this case, the plaintiff will argue, using evidence from e-mail exchanges, that she had been promised a lucrative Japan Science and Technology Corporation special research grant that would more than double her pay. She also claims that her division head had told her it would be possible to extend her three-year position for "a long time", and that he promised her a subsidy from his research fees.

As is common in Japan, none of this was written into an official contract. "In Japan,
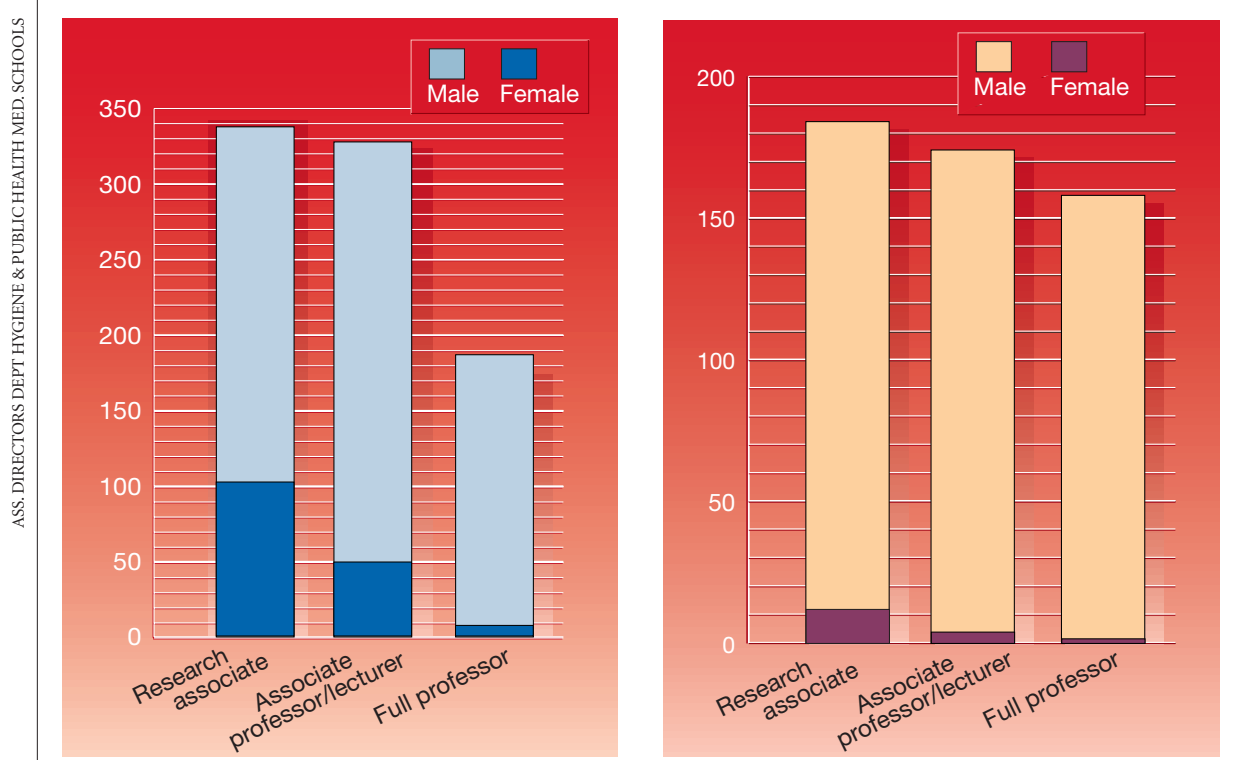

Glass ceilings: the discrepancy between the sexes in Japan is clearly visible in surveys of the number of researchers in university public health/medical schools in 2000 (left) and in astronomy in 1999.

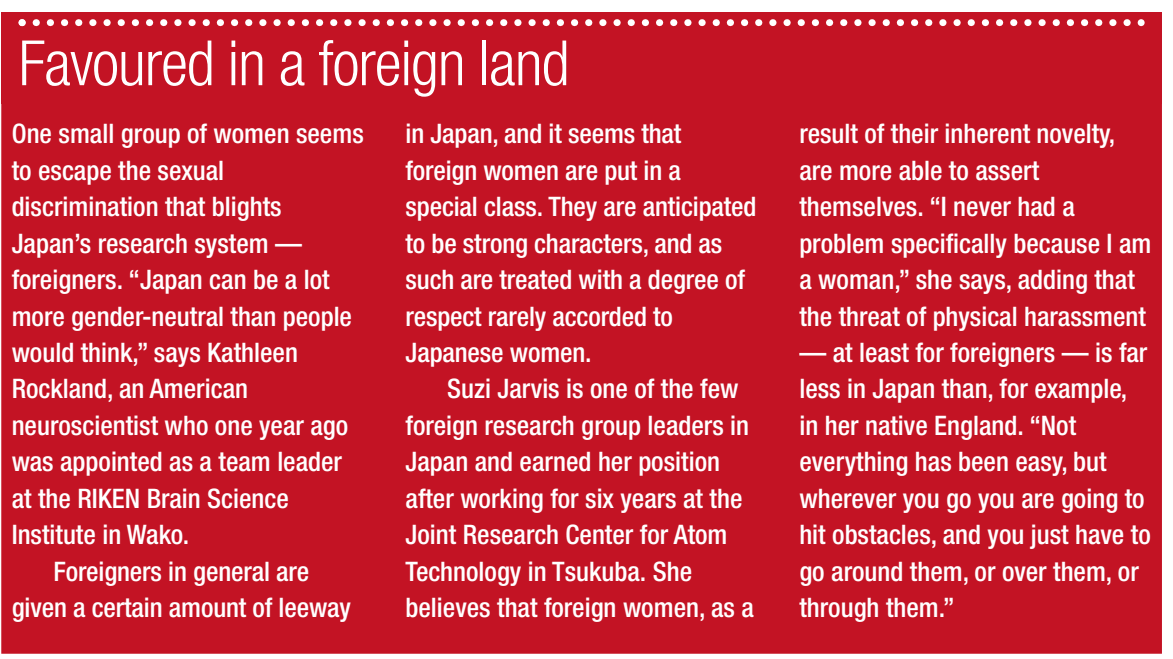

the employee has no choice but to believe what such a high-ranking official claims to be able to offer," says Minoru Wakabayashi, a lawyer involved in the suit, which has been filed against both the division head and the Japanese government. The division head argues that he only said the grant would go to the plaintiff because he assumed no one else at the institute would apply.

Following her legal victory last year, Ogoshi continues to fight the cause of junior researchers - especially women — who are foiled in their attempts to reach the upper echelons. Last month, her organization of research associates petitioned the government to establish a non-profit group to collect data on the status of women scientists. "The fact that there are so little data collected on this issue shows that it is not considered socially significant," says Ogoshi. But there are some signs of change. The science ministry, for example, has this year started to break down data on its grant-in-aid recipients by sex.

Go, as the senior member of the Division

^๔ 2001 Macmillan Magazines Ltd of Biological Science at Nagoya University, has reached the top of her profession, and was last month elected onto the university's governing senate. Although conditions at Nagoya are better than at other universities, says Go, there is still room for improvement. Go will retire in two years, and she intends to increasing opportunities for women by encouraging them to apply and ensuring that they are given fair hearings for promotions and new positions.

Kato, meanwhile, is turning her attention to another iniquity of the science ministry's grants-in-aid system. At the moment, the ministry only accepts applications from those holding a permanent position, which Kato says discriminates against the many women who are left stranded in temporary research posts. "It exacerbates the problem of the predominantly female researchers who are unable to get a permanent position," she says.

Go and Kato are also trying to create a more favourable environment for women through their scientific societies. Encouraged largely by Kato, the Astronomical Society of Japan established nurseries at its conferences so that mothers with young children can attend. The Biophysical Society of Japan, whose president is Go, and several other societies have now followed this lead.

But such moves, although welcome, leave women scientists intact. And breaking that will require a sustained and aggressive assault — something that will not be popular in Japan. During interviews for this article, several women who have serious gripes about their situation nevertheless expressed reservations about moving to a system in which, as one put it, "people are always complaining in order to get what they want".

Researchers such as Go have learnt to accept that victory will not come easily."There is a deep psychological bent in many men in Japan," says Go. "They just feel more comfortable without women as colleagues."

David Cyranoski is Nature's Asian-Pacific correspondent. devote her remaining time in employment to the system that frustrates the ambitions of 